\title{
Esperando por uma tributação ideal: o imperativo categórico da capacidade contri- butiva
}

\section{Waiting for an ideal tax: the categorical im- perative of the ability to pay principle}

\author{
André Felipe Canuto Coelho ${ }^{1}$ \\ Bruna Estima Borba ${ }^{2}$
}

Resumo: O presente artigo pretende examinar as possibilidades e as características da tributação ideal associando-a à tributação justa. Utilizando o método dedutivo e pesquisando a doutrina, a jurisprudência e as normas jurídicas, este artigo procura aproximar a tributação justa do princípio da capacidade contributiva. Mediante uma apreciação histórica do fenômeno da tributação associado a manifestações da capacidade econômica, pretende-se demonstrar que, em Estados

1 Graduado em Economia e em Direito pela Universidade Federal de Pernambuco, mestre em Direito pela Universidade Federal de Pernambuco e Doutor em Ciência Política pela UFPE. Professor da Faculdade Damas de Instrução Cristã na graduação e no Mestrado do Curso de Direito na área de Tributário, Financeiro e Econômico. E-mail: afccbgp@hotmail.com

2 Professora do Adjunta de Direito Tributário e de Direito Financeiro da Universidade Federal de Pernambuco (UFPE). Professora da Faculdade Damas da Instrução Cristã em Recife. Possui mestrado (2004) e doutorado em Direito (2011) pela Universidade Federal de Pernambuco . Auditora fiscal da Receita Federal do Ministério da Fazenda aposentada.

E-mail: brunaestimaborba@gmail.com 
fiscais de economia capitalista, a tributação ideal será justa se conformada à manifestação da riqueza tributável do indivíduo.

Palavras-chave: tributação; economia; riqueza; capacidade econômica; capacidade contributiva

Abstract: This paper intends to verify the possibilities and the features of the ideal taxation trying to associate it with a fair one. Using the deductive method as well as making references to doctrines, jurisprudences and legal norms, this study aims to associate the fair taxation to the ability to pay principle. Through a historic perspective trying to link the taxation phenomena to several forms of economic capacity, it's proposed that, in fiscal capitalistic States, a fair taxation could be achieved if it's goes hand in hand with an individual's taxable expression of wealth.

Keywords: taxation; economics; wealth; economic capacity; ability to pay

\section{Introdução: a tributação ideal em função de seus efeitos econômicos}

A questão da tributação ideal tem ocupado doutrinadores e governantes por séculos ${ }^{3}$. Todavia, assim como esperavam por Godot os personagens Estragon e Vladimir ${ }^{4}$, assim espera a humanidade pela distribuição justa do ônus de financiar o Estado.

Não se tratará neste estudo da justiça fiscal em sentido amplo ${ }^{5}$, assim compreendidas a obtenção e a distribuição de recursos pelo Estado. Tampouco será aqui examinada a

\footnotetext{
3 SANCHES, 2010, p. 19.

4 BECKETT, 1952.

5 SIDOU, 1978, p. 130.
} 
ideia de justiça social, que nas palavras de Lacerda ${ }^{6}$, "deve ser compreendida como algo mais que o direito a certo nível de bem-estar material, pois é dever da sociedade política distribuir também educação e bens culturais àqueles que não os possuem".

Ainda assim o tema é bastante amplo, tornando necessária sua delimitação. Entre os olhares através dos quais se pode examinar a justiça dos tributos, apresentam-se o temporal, o geográfico, o político, o jurídico, o funcional, o social e o econômico ${ }^{7}$.

Portanto, a compreensão do que pode representar uma justa tributação exige um corte epistemológico. No presente caso, as conclusões extraídas deste estudo e sua aplicabilidade se limitarão às sociedades que se apresentem sob a forma de um Estado fiscal social e nas quais o direito à propriedade privada é juridicamente previsto e garantido ${ }^{8}$.

Do ponto de vista político não se refuta o pensamento de poderem representar, os tributos, formas de exploração econômica e instrumentos de dominação capazes de controlar um sistema de classes ${ }^{9}$. Contudo, se essas afirmações são verdadeiras, o oposto será igualmente verdade, podendo-se afirmar que os tributos podem ser instrumentos de redistribuição de riqueza e de realização da solidariedade social, permitindo a mobilidade de classes e o desfrute, por essas classes, de novas utilidades e liberdades.

Esse estudo visa, portanto, ao buscar a compreensão do fenômeno da tributação, direcioná-la à concretização dessas outras funções, afastando-a do exercício dos papéis criticamente apontados por $\mathrm{O}^{\prime}$ Connor. Afastam-se também

6 LACERDA, 2016, p. 309.

7 BOUVIER, 2002, p. 18-19.

8 MURPHY; NAGEL, 2005, p. 11.

9 O'CONNOR, 1977, p. 203-204. 
as denominadas teorias antifiscais que negam a necessidade de qualquer tributação ${ }^{10}$ a exemplo das escolas da chamada public choice ${ }^{11}$, que pregam o estado mínimo, o liberalismo extremado e a total privatização dos serviços públicos.

No que se refere ao aspecto jurídico, a tentação de associar a tributação justa àquela que atenda ao princípio da legalidade - a certeza da instituição e modificação de tributos por meio da lei, pressupondo a representatividade do legislador ordinário - deve ser combatida. Se assim fosse, bastaria a qualquer sistema tributário o requisito formal - no caso brasileiro, a edição válida de lei ordinária, lei delegada, medida provisória ou lei complementar quando exigida, não atingidas por juízo de inconstitucionalidade - para se considerar justa a exação ${ }^{12}$.

Tampouco se investigará a justiça da tributação em seu aspecto funcional, isto é, no âmbito da administração tributária e da prestação jurisdicional. Não se perquirirá sobre aplicação igualitária da lei - a igualdade formal - a segurança jurídica do cidadão e o respeito a seus direitos e garantias, a exemplo da possibilidade de impugnar a exigência utilizando-se da ampla defesa, do contraditório e do duplo grau de jurisdição. Igualmente não se analisará a eficiência do sistema tributário, deixando de lado perguntas relativas à sonegação fiscal e à efetividade das cobranças administrativas e das execuções fiscais ${ }^{13}$. Por fim, as condições sociais de aceitação da tributação não serão objeto de exame, ainda que se encontre assentado por renomados doutrinadores que um imposto ideal deve ser aquele surtout et avant tout l'impôt qui est reconnu comme légitime au sein d'une société donnée $\mathrm{e}^{14}$.

10 FRANÇA, s/d, p. 6-7.

11 Teoria da escolha pública (tradução nossa). BUCHANAN; TOLLISON, 1984.

12 REALE, 1994, p. 105-106.

13 IPEA, 2011, p. 16-17 (b).

14 Sobretudo e antes de tudo um imposto reconhecido como legítimo no âmbito 
Como explica Sen ${ }^{15}$ citando o teorema da impossibilidade de Kenneth Arrow, nem sempre as decisões democráticas da maioria são justas.

Ainda assim, diversos perfis de contribuintes podem gerar diferentes posturas perante os tributos, independentemente da capacidade contributiva de que forem detentores o homem econômico, o equilibrista, o leigo, o mal-humorado, o legalista, o liberal, o sensível e o beneficiário ${ }^{16}$.

Se no Egito do século XIII aC o faraó Akhenaten e os sacerdotes obtinham o privilégio de não pagar tributos mediante associação pessoal a uma diversidade de divindades entre as quais o astro solar Aten ${ }^{17}$, no Brasil atual tampouco pagam impostos os templos de qualquer culto em razão da imunidade religiosa ${ }^{18}$. Em suma, ainda que fatores culturais e políticos influam sobre o que se pode considerar em determinada sociedade uma justa tributação, não serão estes os aspectos objeto da análise, mesmo porque eles nada dizem acerca da justiça quanto à exigência de tributos.

Neste artigo se supõe que os indivíduos concordam em submeter seus interesses privados em favor do interesse público por meio do pagamento de tributos, estando presentes os requisitos mínimos de: (i) a legitimidade do governo a que esses tributos servem; (ii) a honestidade dos servidores da administração tributária; e (iii) um conjunto de normas tributárias que reflitam a moderação na exigência dos tributos associada à isonomia ou igualdade fiscal ${ }^{19}$.

O exame da tributação ideal se assemelha a um delimitado palco teatral em que personagens serão chamados

de uma determinada sociedade (tradução nossa). BOUVIER, 2002, p. 16

15 SEN, 2010, p. 320-321.

16 TIPKE, 2002, p. 112-125.

17 ADAMS, 2001, p. 5-16.

18 BRASIL, 2012.

19 WEBBER, WILDAVSKY, 1986, p. 143. 
a atuar para que suas representações possam iluminar a compreensão do assunto.

Nesse palco quem deve entrar em cena? A escolha deve recair sobre os elementos que informam as bases de incidência da tributação. $\mathrm{O}$ aspecto econômico dos tributos será, portanto, o protagonista.

Utilizando o método dedutivo e a pesquisa em perspectiva histórica e auxiliado por algumas expressões da realidade - normas jurídicas, dados estatísticos e jurisprudência - este artigo procura aproximar a tributação justa do princípio da capacidade contributiva. Parte-se de pressuposto de que todos podem e devem enriquecer, sendo certo igualmente que ninguém, em lugar nenhum, pode se beneficiar de sua riqueza - obtida pelo congraçamento de suas dotações originárias, de seus esforços, de seus talentos, de suas oportunidades, e da natureza que é patrimônio de todos - sem compartilhar parte dela com a coletividade.

Faz-se necessário distinguir a capacidade econômica, significando a igual exteriorização de riqueza capaz de atribuir ao contribuinte a aptidão em potencial para pagar o tributo, da capacidade contributiva que compreende a dimensão particular e subjetiva do indivíduo representando sua riqueza idônea a ser tributada ${ }^{20}$.

Ora, sendo a capacidade econômica um atributo objetivo do sujeito, é condição necessária, mas não suficiente para habilitá-lo a contribuir, sendo a capacidade contributiva a condição necessária e suficiente para o pagamento do tributo ${ }^{21}$.

20 GIARDINA, 1961, p. 3; SOUSA, 1960, p. 71; MARTINS, 1989, p. 33.

21 MOSCHETTI, 1973, p. 238-240. 
A capacidade contributiva é, ademais, o critério para graduação da exigência tributária a ser exigida do cidadão ${ }^{22}$. Enquanto a capacidade econômica possibilita a realização da equidade vertical ou formal da tributação, a capacidade contributiva visa à concretização da igualdade horizontal ou material ${ }^{23}$ pois, em que pese ambas se originarem de um acontecimento de natureza econômica, é a capacidade contributiva que torna o sujeito apto a pagar o tributo, permitindo que se compare o ônus da tributação sofrido por dois indivíduos e o atendimento ao princípio da isonomia tributária ${ }^{24}$.

Para Nabais ${ }^{25}$, sequer há necessidade de se referir à capacidade contributiva, por ser ela decorrência direta da igualdade em sua concepção material derivada do conceito aristotélico de equidade. Para o autor, a capacidade contributiva deve ser o critério de repartição do ônus tributário, pois o que é essencialmente igual deve ser tributado igualmente e o que é essencialmente desigual deve ser tributado desigualmente na medida dessa desigualdade.

Por fim, em face da capacidade contributiva se contrapõe, por ponderação, o princípio da proibição do confisco para preservar o mínimo vital ${ }^{26}$.

Para exemplificar, tome-se o caso do Imposto de Renda das Pessoas Físicas (IRPF) do Brasil, em que a capacidade econômica do contribuinte dependerá de sua renda bruta, enquanto a capacidade contributiva decorrerá de sua renda líquida, ou seja, da diferença entre a renda bruta e as despesas consideradas necessárias à manutenção da vida digna

22 GANZÁLEZ, PEREZ DE AYALA, 1978, p. 181.

23 MURPHY; NAGEL, 2005, p. 18.

24 ESCRIBANO, 1988, p. 199, CASTRO, 1910, p. 154.

25 NABAIS, 1998, p. 442-445.

26 COSTA, 2003, p. 79 
do sujeito ${ }^{27}$. Atualmente são dedutíveis os gastos previstos na Lei ${ }^{0}$ 7.713/1988: contribuição para a previdência social, contribuição para a previdência privada, dependentes, despesas médicas, despesas com instrução, despesas de livro caixa e pensão alimentícia judicial paga em razão do direito de família.

A conclusão de ser a tributação justa aquela conformada à capacidade contributiva individual e concreta do sujeito reconhece, implicitamente, a desigualdade de capacidades e, portanto, a existência de desigualdades. Tal fato social pode ser legitimado em face de escolhas efetuadas a partir de uma dotação inicial igualitária de recursos ${ }^{28}$. Como assume Einaudi, la igualdad es axiomática ${ }^{29}$ pois em uma sociedade inteiramente igualitária não caberia falar em desigualdade ${ }^{30}$.

A capacidade contributiva deve, assim, ser o princípio máximo da tributação, o imperativo categórico, pode-se dizer, do sistema tributário justo.

\section{A capacidade contributiva: o que a história pode mostrar?}

O fenômeno da tributação é antigo, no sentido histórico da palavra ${ }^{31}$. Os tributos acompanham a humanidade há milênios, como demonstra a origem da própria palavra encontrada no latim da Roma antiga, distinguindo-se os tributos internos, incidentes sobre o próprio povo - tributum ${ }^{32}$

27 OLIVEIRA, 2008, p. 434-436.

28 DWORKIN, 2012, p. XVII e 133.

29 A igualdade é axiomática (tradução nossa).

30 EINAUDI, 1959, p. 234.

31 WEBBER, WILDAVSKY, p. 17.

32 Tributo (tradução nossa). 
exigido dos cidadãos romanos com base no patrimônio e por meio das alíquotas simplex ${ }^{33}(1 \%)$, duplex ${ }^{34}(2 \%)$ e triplex $x^{35}(3 \%)$ e capite censi ${ }^{36}$, sendo um valor fixo pago por indivíduo - , assim como a tributação externa, o stipendium ${ }^{37}$ anual exigido dos povos vencidos nos territórios ocupados ${ }^{38}$.

Contudo, a denominação é o que menos importa, posto que a tributação sempre esteve no encalço da capacidade econômica, assim compreendida qualquer manifestação de riqueza que se apresentasse apta a ser tributada. Essa relação umbilical entre riqueza e tributação não comportava, até o início do século XX, qualquer apreciação sobre a capacidade contributiva ou aptidão real e concreta para pagar o tributo por parte do sujeito onerado.

Por outro lado, foi a economia a rota por onde caminhou a tributação e por onde ainda hoje passeia a humanidade $^{39}$. De fato, nesse palco que é a vida do homem sobre a terra, o protagonismo cabe à ciência da escassez e à sua contínua e perpétua tarefa de produzir riquezas e decidir sobre sua distribuição.

Essa riqueza é, antes de mais nada, a riqueza tributável sobre a qual se impõe a tributação e, tendo em vista que as formas de produção de riqueza têm se alterado ao longo do tempo e que variam em função do lugar, abrangendo o setor primário - agricultura e pecuária -, secundário - indústria extrativa, de transformação, de construção e de serviços industriais - e terciário - comércio e serviços de transporte,

33 Simples (tradução nossa).

34 Duplo (tradução nossa).

35 Triplo (tradução nossa).

36 Por pessoa (tradução nossa).

37 Estipêndio (tradução nossa).

38 ADAMS, 2001, p. 81-85.

39 SELIGMAN, 1973, p. 124. 
comunicações e de instituições financeiras ${ }^{40}$ - é natural e mesmo desejável que os tributos assumam aspectos diversos, acompanhando as distintas formas de manifestação de riqueza.

A história mostra, por outro lado, que a incidência da tributação sobre a riqueza, ou seja, a prevalência do princípio da capacidade econômica é fruto de fatores igualmente pragmáticos que têm por objetivo a obtenção da maior arrecadação ao menor custo possível. Esse é, inclusive, um dos cânones da tributação conhecido por princípio da economicidade da tributação ${ }^{41}$.

$\mathrm{Na}$ antiguidade, enquanto a exigência de tributos externos se apoiava na força caracterizando-se como pura expropriação, a tributação interna requeria alguma legitimação, ainda que nos dois casos consistisse em ato de império e não de consentimento ${ }^{42}$.

Em outras ocasiões, eram instituídos tributos por razões mais palpáveis, a exemplo das contribuições para o esforço de guerra exigidas dos romanos com base em censos realizados a cada cinco anos. Cabia ao cidadão informar corretamente sua riqueza tributável, sob pena, inclusive, de ser vendido como escravo pelo censor ${ }^{43}$.

Na Alta Idade Média predominavam tributos incidentes sobre a riqueza produzida pela terra e pagos in natura $a^{44}$, como a coletas ${ }^{45}$ recolhida per capita ${ }^{46}$ sob regime de cotisation ${ }^{47}$,

\footnotetext{
40 VASCONCELLO, 1991, p. 199.

41 SMITH, 1988, p. 101.

42 VANONI, s/d, p. 13.

43 GODOI, 1999, p. 81.

44 Em produtos, em bens (tradução nossa).

45 Contribuição pecuniária (tradução nossa).

46 Por pessoa (tradução nossa).

47 Quotidade (tradução nossa). BOUVIER, 2002, p. 19.
} 
a taille ${ }^{48}$ consistindo no pagamento in natura ${ }^{49}$ de $50 \%$ do que fosse produzido pelo servo, a mão morta, um tributo pago pelo filho do vassalo para que pudesse permanecer no local após o falecimento do pai; a corveia paga in labore ${ }^{50}$ correspondente ao trabalho por três ou quatro dias para o senhor feudal; as banalidades ou pagamento pelo uso das instalações do castelo como o moinho, o forno e o poço; além do Tostão de Pedro pelo qual se destinava $10 \%$ da produção do servo para a Igreja ${ }^{51}$.

A nobreza, quando chamada a pagar tributos - o scuta$g e^{52}$ - sob a forma de contribuição para guerras de conquista ou defesa, tratou rapidamente de limitar o poder tributário. O resultado foi o art. 12 da Carta Magna de $1215^{53}$, considerado a certidão de nascimento do princípio da legalidade, ainda que Platão já mencionasse as leis e sua necessidade ${ }^{54}$.

Para a escolástica, a legitimação dos tributos deveria atender a quatro razões: a causa eficiente (a soberania), a causa final (o uso dos recursos para realização do bem comum), a causa formal (a relação justa entre o valor do tributo e o bem por ele proporcionado) e a causa material (a pessoa ou atividade tributável $)^{55}$. Porém, foram razões econômicas - o mercantilismo, a metalização e a exploração colonial - que, trazendo ao palco novas formas de produção de riqueza, permitiram o surgimento de novas fontes de obtenção de receitas tributárias ${ }^{56}$. A própria Summa Theologica mencionava

\footnotetext{
48 Talha (tradução nossa).

49 Em produtos, em bens (tradução nossa).

50 Mediante trabalho (tradução nossa).

51 SARTORI, 2006, p. 45-59.

52 Escudo (tradução nossa). SARTORI, 2006, p. 45-59.

53 INGLATERRA, 1215.

54 PLATÃO, 1975.

55 GRIZIOTTI, 1953, p. 348.

56 PINHO, 1991, p. 6-8.
} 
o pagamento secundum facultatem ${ }^{57}$ ou secundum equilitatem proportions $s^{58}$. Tudo isso muito longe de qualquer preocupação com a tributação ideal, no sentido da justa repartição do ônus de pagar tributos.

Com a afirmação da ordem estatal europeia em $1648^{59}$ acompanhada da unificação dos territórios e da delimitação de espaços de poder mais claramente definidos, os países passaram a comercializar entre si, aumentando a tributação sobre operações externas - hoje os impostos de importação e exportação.

Em 1673, Pufendorf afirmava que os tributos deveriam ser pagos por todos os que usufruíssem da proteção do Estado. Era a semente da tributação contraprestacional que se instauraria na passagem do Estado patrimonial - em que predominam receitas públicas originárias - para o Estado Fiscal financiado por receitas públicas derivadas, não sem antes atravessar o Estado de Polícia que resultou da exploração do povo pelo poder do Príncipes ${ }^{60}$. Mas Locke afirmava em 1689 que uma tributação sem autorização do povo representava afronta à lei fundamental da propriedade ${ }^{61}$.

Montesquieu traçaria, em 1748, os princípios da tributação que, àquela época, visavam ao enriquecimento do erário régio. Indicavam assim, que os tributos deveriam ser fáceis de cobrar e claramente estabelecidos, exemplificando: uma porção sobre os frutos da terra, uma proporção das mercadorias, uma taxa por cabeça, correspondendo às alíquotas ad rem $^{62}$ e ad valorem ${ }^{63}$ respectivamente ${ }^{64}$.

57 Segundo a possibilidade (tradução nossa).

58 Segundo a equitativa proporcionalidade (tradução nossa).

59 KOSELLECK, 1999, p. 45.

60 BERCOVICI, 2001, p. 80.

61 LOCKE, 1978, p. 90.

62 Alíquotas específicas (tradução nossa).

63 Alíquotas proporcionais (tradução nossa).

64 MONTESQUIEU, 2000, p. 227. 
$\mathrm{Na}$ Inglaterra de 1750, as revoltas eram frequentes, pois camponeses e pobres urbanos atacavam mercadores locais e roubavam armazéns, movimentos que foram sabiamente contornados pelas Poor $\mathrm{Laws}^{65}$, que vigoraram naquele país desde os anos 1600 até o século XX quando foram incorporadas pelo sistema de assistência social do país ${ }^{66}$. Pensadores como David Hume defendiam a tributação que preservasse o mínimo necessário à sobrevivência do cidadão. Naquele contexto, a justiça fiscal significava a universalidade, isto é, a contribuição por parte de toda a sociedade, vez que as despesas do Estado beneficiam a todos: "um tributo que é mais igual e mais geral é o mais justo"67.

Elegia-se, portanto, a tributação indireta como a imposição justa no que se denomina atualmente igualdade vertical, ou igualdade perante a lei.

$\mathrm{Na}$ França, as contratações representadas pela Ferme Générale $^{68}$ concediam aos particulares o poder de tributar que implicava o leilão e a arrematação de regiões inteiras para fins de tributação por parte de ricos comerciantes e agricultores pelo maior lance, ou seja, por aquele que oferecesse ao governo o maior valor, levando a população ao desespero e à sangrenta Revolução Francesa ${ }^{69}$.

O humanismo, o movimento constitucionalista e a afirmação de direitos fundamentais - liberté, egalité et fraternitéto - limitou sem dúvidas o poder do Estado sobre o indivíduo, reafirmando a exigência da legalidade relativamente à im-

65 Leis dos Pobres (tradução nossa).

66 INGLATERRA, s.d.

67 WEBBER, WILDAVSKY, 1986, p. 273.

68 Fazenda Geral (tradução nossa). FRANÇA, 2014.

69 SANCHES, 2010, p. 27.

70 Liberdade, igualdade e fraternidade (tradução nossa). BRANDÃO, 2014, p. 13. 
posição tributária sem resolver, absolutamente, a questão da justa distribuição do ônus da tributação.

A presença do Estado fiscal financiado principalmente por receitas derivadas tornava ultrapassado o conceito de Estado patrimonial - financiado principalmente por receitas originárias - e foi fenômeno próprio da transição dos séculos XVIII para o XIX ${ }^{71}$. Paralelamente, a atividade econômica passava a ser cientificamente estudada debruçando-se os economistas sobre as possibilidades de enriquecimento das nações e, consequentemente, da coletividade, com um otimismo baseado no livre funcionamento dos mercados instaurando as correntes liberais do pensamento econômico.

Surgia, assim, a ciência das finanças e seus estudos voltados para a compreensão do enriquecimento do Estado, o que evidentemente abrangia suas fontes de financiamento. Aflorava a preocupação com a tributação ideal, ainda que visando ao enriquecimento do erário, agora público. Permanecia esquecida, contudo, a justiça na repartição do financiamento estatal.

É dessa época a fisiocracia e os pensadores que, a exemplo de François Quesnay ${ }^{72}$, propunham no final do século XVIII a tributação única sobre a terra nua.

A escola Clássica ${ }^{73}$ que se seguiu aos fisiocratas pode ser representada por Adam Smith que, no campo tributário, teve o mérito de indicar os quatro cânones da tributação expostos na Riqueza das Nações ${ }^{74}$. A tributação ideal seria aquela que gerasse menores custos para a administração tributária e também para o contribuinte, a que levasse todos a contribuir e, por fim, a contribuir conforme suas capacidades.

71 TORRES, 1991, p. 97-98.

72 PINHO, 1991, p. 9.

73 PINHO, 1991, p. 11.

74 SMITH, 1988, p. 99-101. 
A tributação conforme a ability to $p a y^{75}$ era sinônimo, então, de proporcionalidade - percentuais fixos sobre bens, rendas e operações - em contraposição à exigência de valores fixos.

A revolta do Chá associada ao ânimo libertário das 13 Colônias americanas em $1773^{76}$ é também o retrato da insurgência dos colonos à tributação que os obrigava a transferir parte de sua riqueza para o império britânico. Nos Estados Unidos da América de 1848, Thoreau escrevia que preferiria ser preso - como de fato foi - a pagar tributos ${ }^{77}$.

Vale notar que, no Brasil, a tributação externa - o imposto sobre importação, denominado à época colonial de Entradas - era o tributo de maior arrecadação no país, correspondendo a $50 \%$ da carga tributária ${ }^{78}$, permanecendo nessa condição até a década de quarenta do século passado. Esse panorama somente se reverteu com a consolidação da economia interna fruto dos esforços de industrialização do governo Getúlio Vargas a partir de $1940^{79}$.

Para uma nação que atravessara séculos de exploração econômica e fora proibida de sediar indústrias e de manter comércio exterior independentemente de Portugal até a abertura dos portos ocorrida somente com a chegada da Corte em 1808, esse foi um feito notável. Todavia, o Brasil, ao contrário de outros países, não teve sua história marcada por revoluções patrióticas para chegar à proclamação da independência em 1822 e à instauração da república em 1889. As grandes lutas nacionais decorreram de questões econômicas e tributárias: a Inconfidência Mineira de $1789^{80}$

\footnotetext{
75 Capacidade contributiva (tradução nossa).

76 ADAMS, 2001, p. 310.

77 THOREAU, 2009, p. 30-35.

78 VARSANO, 1997, p. 2-6.

79 AMED; NEGREIROS, 2000, p. 256-269.

80 AMED; NEGREIROS, 2000, p. 157-161.
} 
e a Revolução Pernambucana de $1817^{81}$, ambas para pôr fim à exploração nacional por Portugal.

O Estado fiscal tornava claro para todos que a sociedade, ainda que livre, era a financiadora do Estado e, consequentemente, dos gastos públicos. Por outro lado, afirmava-se a 'razão do Estado' que legitimaria a exigência de tributos não mais fundada no jus imperii ${ }^{82}$, mas no interesse público ${ }^{83}$.

Diferenciavam-se assim as relações jurídicas que tinham por objeto a prestação tributária: de modo contraprestacional (taxas) ou independentemente de retribuição estatal (impostos); correlacionadas ao custo do Estado para realizar a ação voltada para o contribuinte (taxas) ou mensuradas conforme uma situação do contribuinte ou uma atividade por ele praticada (impostos). Ou ainda, cuja arrecadação seria destinada a uma atividade estatal específica associada à cobrança do próprio tributo (taxas) ou, ao contrário, desvinculada de qualquer destinação especial, tendo por fim custear despesas gerais da coletividade (impostos) ${ }^{84}$, correspondendo às chamadas teorias do benefício e do sacrifício, respectivamente ${ }^{85}$.

O impôt-échange, impot-assurance ou impôt-contrepartie $e^{86}$ exige dos contribuintes o pagamento pelas utilidades a ele fornecidas pelo Estado. Baseia-se na ideia de equivalência do tributo em função da utilidade fornecida pelo Estado ao contribuinte e é realizadora da justiça comutativa em contraposição à justiça distributiva que se instauraria posteriormente juntamente com a teoria do sacrifício ou da solidariedade da tributação.

81 AMED; NEGREIROS, 2000, p. 187.

82 Direito de exercer a autoridade (tradução nossa).

83 TORRES, 2016, p. 222-223.

84 SANCHES, 2010, p. 21.

85 MUSGRAVE, 1995, p. 193.

86 Os três termos, sinônimos, são traduzidos como tributos contraprestacionais. 
Inspirada no contratualismo do Leviatã de Thomas Hobbes, a tributação contraprestacional deveria ser proporcional: quand les impôts sont assis sur ce que les gens consomment, chacun paie également pour ce dont il use et la république n'est pas frustée par le gasillage de certains particuliers ${ }^{87}$.

Há basicamente três críticas a essa forma de tributar: (i) a desconsideração à natureza solidária da vida social; (ii) a impossibilidade de se mensurar o custo individualizado da prestação de diversos serviços públicos, a exemplo da segurança pública; e (iii) o fato de a maior parte dos beneficiários de serviços públicos serem justamente os cidadãos menos dotados economicamente, o que levaria essa parcela da população a pagar mais ${ }^{88}$.

A teoria comunitarista do imposto solidariedade, contudo, somente surgiu no final do século XIX como reação à tributação contraprestacional ${ }^{89}$ e como decorrência lógica da indicação da capacidade contributiva como critério para exigência de tributos no art. 13 da Declaração de Direitos de $1789^{90}$. Em mais uma reviravolta tributária, passava-se da teoria do benefício à teoria do sacrifício ${ }^{91}$.

Considera-se parte dos primeiros estudos sobre a questão da justiça fiscal a publicação em 1874 por Emile-Justin Menier do livro L'Impôt sur le Capital ${ }^{92}$, além da edição em

87 Quando os tributos incidem sobre o que as pessoas consomem, cada um paga igualmente por aquilo de que desfruta e a república não se vê frustrada pelo desperdício de certos indivíduos (tradução nossa). HOBBES, 1651, p. 15-23,

88 FRANÇA, s/d, p. 9.

89 FRANÇA, s/d, p. 3.

90 FRANÇA, 2005.

91 MURPHY, NAGEL, 2005, p. 22-30.

92 Imposto sobre o Capital (tradução nossa). 
1878 por Henry George da obra Progrès et Pauvrete ${ }^{93}$, ambos tratando da tributação sobre o patrimônio ${ }^{94}$.

É dessa época, também, a distinção formal das bases de incidência da tributação, correspondendo a distintas manifestações de riqueza, ou seja, a diferentes exteriorizações de capacidades econômicas: (i) o patrimônio ou a riqueza acumulada; (ii) a renda ganha nas diversas modalidades de rendimentos de natureza salarial e de capital; (iii) a renda gasta ou consumo, indicador da diferença entre renda ganha e renda poupada; (iv) a tributação indireta, isto é, a atividade econômica de produção e circulação de bens e serviços.

Coube à Alemanha precisar a relação entre fato econômico e tributação. Na redação do Código Tributário Alemão de 1919, Enno Becker evidenciou a natureza econômica do fato gerador como manifestação de riqueza passível de ser tributada independentemente da forma jurídica de que se revestisse o ato ou o negócio jurídico praticado. Em um país que necessitava recuperar-se do fracasso da $1^{a}$ guerra mundial, tornava-se premente a obtenção da maior arrecadação possível devendo, consequentemente, se considerar para fins de exigência tributária o conteúdo econômico dos fatos jurídicos, não sua forma. Em 1924 Albert Hensel, então professor da Universidade de Bonn, escreveria sua principal obra (1956) traçando a estrutura doutrinária do direito tributário, criando na doutrina o que o Código de 1919 havia produzido na lei. Entre tais institutos, conceitos e princípios, estava o da interpretação econômica do fato gerador. Em razão de sua origem judaica - sua avó paterna era irmã do músico Felix Mendelsohn - Albert Hensel foi excluído de sua cátedra em Königsberg e levado a mudar-se em 1933 para a Itália, instalando-se em Pavia onde veio a falecer no mesmo

93 Progresso e Pobreza (tradução nossa).

94 FRANÇA, s/d, p. 4. 
ano ${ }^{95}$. Afirmava-se a ideia de que o fato gerador dos tributos retrataria um fato jurídico que seria, ao mesmo tempo, um acontecimento econômico cuja existência era suficiente para determinar o nascimento da obrigação tributária, qualquer que fosse a disciplina a ele dada pelo direito privado ${ }^{96}$. A capacidade contributiva era, assim, a causa jurídica do fato imponível ${ }^{97}$.

No início do século $X X$, já restara esclarecida a natureza socialmente injusta dos tributos contraprestacionais e a adequação dos impostos à repartição mais isonômica do ônus tributário. Contudo, era ainda necessário enfrentar a questão da regressividade da tributação indireta, assunto que foi esclarecido igualmente com auxílio da economia. $\mathrm{O}$ conceito de propensão marginal a consumir ${ }^{98}$ evidenciaria a regressividade da tributação indireta que até então, por se caracterizar por um valor ou percentual fixo sobre a operação tributável, era tida como compatível com a capacidade contributiva.

Nada mais contrário: sendo a propensão marginal a consumir tanto maior quanto menor a renda do indivíduo, aqueles que ganham menos gastam proporcionalmente mais, e consequentemente, pagam mais impostos indiretos. De onde se conclui que a tributação indireta atua regressivamente sobre a renda e, portanto, fere o princípio da capacidade contributiva ${ }^{99}$.

Ademais, em razão da repercussão própria dos tributos indiretos, não há possibilidade de se verificar a adequação do tributo à capacidade do consumidor, adquirente do bem ou serviço.

95 GRIZIOTTI, 1956 , p. IX.

96 JARACH, 2004, p. 107 e 115.

97 JARACH, 2004, p. 125.

98 SAMUELSON, 1979, p. 176 e 224.

99 PEREIRA, 2009, p. 68. 
Some-se a esses fatores a invisibilidade desses tributos que, por inseridos nos preços dos produtos, tendem a ter seu peso econômico ignorado pelo consumidor, contribuinte de fato. Essa característica já fora apontada pelo Pe. Antônio Vieira, em seu sermão às Cortes Portuguesas de 1642, quando explicou ser bem mais fácil exigir tributos indiretos que cobrá-los diretamente em função do patrimônio ou renda. Em uma referência à criação de Eva a partir da costela de Adão, explicava que Deus adormecera o homem para que não sentisse a perda, ainda que tudo se fizesse para seu próprio bem. Concluía o religioso que, da mesma forma deveriam ser exigidos os tributos: "tire-se com tal modo, com tal indústria, com tal suavidade, que os homens não o sintam nem quase o vejam" ${ }^{100}$. Bem antes, Nero já reconhecera a invisibilidade dos tributos indiretos anunciando a supressão da vigésima quinta parte exigida sobre a venda dos escravizados. No entanto, ele só havia atribuído ao vendedor a obrigação de recolher o tributo - que já o incorporava ao preço - quando antes cabia ao comprador fazê-lo ${ }^{101}$.

De fato, a tributação direta somente se implantaria a partir do século dezoito pois, até então, a ela se recorria esporádica e emergencialmente ${ }^{102}$.

No que concerne à incidência econômica dos tributos, até o final do século XIX, os impostos, quando diretos, possuíam natureza essencialmente real - e não pessoal - ou seja, incidiam sobre o patrimônio e a riqueza do particular, que estavam, em geral, associados à propriedade da terra ${ }^{103}$. Correspondiam ao land $\operatorname{tax}^{104} \mathrm{e}$ ao assessed $\operatorname{tax}^{105}$, o primeiro

100 NABAIS, 2003, p.750-751.

101 MONTESQUIEU, 2000, p. 225.

102 SABINE, 1966, p.11.

103 SELIGMAN, 1913, p. 5.

104 Imposto sobre a propriedade territorial (tradução nossa).

105 Imposto sobre o patrimônio (tradução nossa). 
incidente sobre a terra e o segundo sobre outros bens - casas e número de janelas, carruagens, animais, talheres, - e mesmo sobre a quantidade de empregados possuídos pelo particular.

Mais uma vez vieram os economistas clarear a questão tributária. O conceito de utilidade marginal decrescente da renda originado do utilitarismo de John Stuart Mill instaurou a progressividade da tributação direta ${ }^{106}$. Sendo o ônus de pagar impostos um sacrifício econômico ao qual todos deveriam se submeter, a isonomia residiria em reparti-lo conforme o sacrifício mensurável em termos de perda da renda, considerando-se sua utilidade marginal decrescente ${ }^{107} \mathrm{e}$ tornando, quanto maior a renda, menor, proporcionalmente, o sacrifício da perda ${ }^{108}$. Em outras palavras, a cada nível de renda corresponderia uma alíquota que equipararia a perda de utilidade do consumo a que deveria renunciar o contribuinte versus o ganho das utilidades de serviços públicos a serem fornecidos pelo Estado financiado pelo tributo pago ${ }^{109}$. Criava-se assim um critério de igualdade horizontal ${ }^{110}$ na tributação, em contraposição à igualdade vertical que antes prevalecera ${ }^{111}$. Passava-se, definitivamente, da capacidade econômica para a capacidade contributiva.

A questão da progressividade requeria alguns ajustes, como a adoção da super-tax ${ }^{112}$ - um percentual adicional aplicável à renda que superasse certo valor - e a fixação de um valor mínimo sobre o qual a alíquota é zero, além de sofrer

106 SILVA, 1974, p. 25.

107 SAMUELSON, 1979, p. 457.

108 SILVA, 1974, p. 29.

109 BERLIRI, 1986, p. 252.

110 HUGON, 1945, p. 74.

111 MURPHY, NAGEL, 2005, p. 18.

112 Adicional de alíquota (tradução nossa). SELIGMAN, 1913, p. 258. 
críticas quanto à elevação excessiva das alíquotas, tornando corriqueira a expressão too much tax kills tax ${ }^{113}$, como demonstrava a curva de Laffer ${ }^{114}$. Nesse contexto evidenciou-se que a tributação progressiva representava uma externalidade econômica causando efeitos redistributivos de renda e dando natureza extrafiscal social ao imposto de renda ${ }^{115}$. Dados relativos à concentração de renda medida por meio da curva de Lorenz coletados antes e depois da incidência do imposto progressivo demonstram o deslocamento da curva para mais perto da linha de igualdade, inclinada a $45^{\circ 116}$, o que confirma sua conformidade com o princípio da capacidade contributiva $^{117}$.

No século $X X$, consolidou-se a compreensão de que taxes are the price we pay for a civilized society ${ }^{118}$. A estreita relação entre economia e capacidade contributiva permitia a construção de um círculo virtuoso: o gasto público elevaria a renda do indivíduo influindo positivamente sobre sua capacidade contributiva, dando lugar à exigência de tributos que, por sua vez, realimentariam os gastos públicos ${ }^{119}$.

A tributação passou a ser orientada não apenas pelo princípio da legalidade e pela proporcionalidade, como também pelo princípio da capacidade contributiva seguindo a teoria do sacrifício, de forma direta e progressiva. Porém, no contexto do Estado Fiscal liberal ${ }^{120}$, permanecia a crítica

113 Tributos em excesso reduzem a arrecadação (tradução nossa).

114 ADAMS, 2001, p. 481-484.

115 SCHOUERI, 2005, p. 150.

116 SAMUELSON, 1979, p. 182.

117 TIPKE; LANG, 2008, p. 202.

118 Tributos são o preço que se paga para viver em uma sociedade civilizada (tradução nossa). IRS, 2017.

119 GRIZIOTTI, 1949, p. 215-216.

120 GODOI, 1999, p. 173-179. 
quanto ao fato de não ser neutra do ponto de vista econômico.

Mais uma reviravolta tributária ocorreria em razão da depressão econômica de 1929, que evidenciou a necessidade da intervenção estatal no âmbito econômico privado, sendo exemplos a criação do FMI e, no campo doutrinário, a publicação da Teoria do Emprego, do Juro e da Moeda. Nessa obra, Keynes defendia a intervenção do Estado na economia indicando a tributação direta, notadamente sobre heranças, como fator econômico favorável à redistribuição de renda e à geração de riqueza por desestimular a acumulação de capital pelos mais ricos e incentivando maior consumo o que, por sua vez, elevaria a renda ${ }^{121}$. Justificava-se então a extrafiscalidade ${ }^{122}$ e a tributação passava definitivamente a exercer outras funções além da arrecadatória, em especial para intervir no domínio econômico - reduzindo importações e incentivando a produção industrial - como também para servir à redistribuição de renda, à reforma agrária, à política urbana, ao apoio ao empreendedorismo e à proteção ambiental.

Coincide o início do século XX com a afirmação do direito tributário como ramo autônomo da ciência jurídica, tendo sido esse momento marcado pela publicação do Código Tributário Alemão de 1919.

No Brasil, o fenômeno da tributação vinha sendo estudado no âmbito do direito financeiro como modalidade de receita pública, tendo passado a objeto de investigação científica a partir da segunda metade daquele século. Sob influência da codificação alemã, foi produzido, em 1954, o Projeto $n^{\circ} 4.834$ do Sistema Tributário Nacional. Posteriormente foi editada a Emenda Constitucional n ${ }^{\circ} 18 / 1965$ à

121 KEYNES, 1988, p. 245-246.

122 PEREIRA, 2009, p. 365. 
Constituição de 1946 estabelecendo um Sistema Tributário Nacional para o País com poucos anos de atraso em relação aos demais países ocidentais. Por fim, em 1966, foi publicado o Código Tributário Nacional, Lei $n^{0} 5.172$, tratando do conceito de tributo, das espécies tributárias e das normas gerais de direito tributário.

Um novo perfil de cidadão surgia no Brasil do século $X X$, correspondendo a trabalhadores qualificados e melhor remunerados, quando antes o trabalho se restringia a atividades pouco remuneradas tornando a força laborativa incapaz de tornar-se contribuintes diretos por ausência de patrimônio e renda suficientes ${ }^{123}$.

É do começo do século XX, também, a instituição definitiva do imposto de renda no Brasil pela Lei $\mathrm{n}^{\mathrm{o}}$ 4.625/1922, após quatro frustradas tentativas anteriores: Lei orçamentária $\mathrm{n}^{\mathrm{o}} 317 / 1843$; Lei n ${ }^{0} 1.507 / 1867$, com o objetivo de financiar a guerra do Paraguai; Lei $n^{\circ}$ 2.321/1910; e Lei $\mathrm{n}^{\mathrm{o}} 2.919 / 1914$. Esse imposto, pessoal e progressivo, tem sua certidão de nascimento assentada na Inglaterra onde foi instituído pelo Heads of a Plan for a Contribution ${ }^{124}$ elaborado por William Pitt em outubro de 1798 e efetivamente cobrado a partir de janeiro do ano seguinte. O income $\operatorname{tax}^{125}$ foi destinado a financiar a guerra contra Napoleão Bonaparte sendo extinto quando do término do conflito em $1816^{126}$. Deve-se reconhecer que, em sua origem, não buscava atender ao princípio da capacidade contributiva, possuindo fins meramente arrecadatórios tanto que, até 1982, o imposto de renda era denominado na Suíça de imposto de defesa ${ }^{127}$.

123 NÓBREGA, 2014, p. 31-35.

124 Marcos do plano de contribuição (tradução nossa).

125 Imposto sobre a renda (tradução nossa).

126 SABINE, 1966, p. 41.

127 TIPKE, LANG, 2008, p. 451. 
O início do século XX foi palco também da afirmação do Estado fiscal social ${ }^{128}$ e da constitucionalização dos direitos sociais, considerados a $3^{\text {a }}$ dimensão de direitos ${ }^{129}$, correlacionados com fraternité1 ${ }^{130}$ que agora aparecia ao lado da liberté ${ }^{131}$ e da égalité ${ }^{132}$, completando o desiderato revolucionário francês.

O século XX transcorreu com uma visão de tributação justa inteiramente distinta daquela afirmada no século anterior: a concepção comunitária dos tributos, no contexto de um Estado ainda fiscal - custeado principalmente por receitas públicas derivadas - mas agora social - voltado para a concretização de direitos sociais constitucionalmente jurisdicizados. As ações positivas do Estado visando à concretização da igualdade por meio da prestação de serviços públicos - saúde, educação, transporte, entre outros - exigia uma conformação plural dos tributos: uma obtenção de receitas eficiente e ao mesmo tempo justa em termos da capacidade contributiva do indivíduo e, aditivamente, sua utilização para fins de promoção da solidariedade social ${ }^{133}$.

A tributação indireta, regressiva em razão da propensão marginal a consumir decrescente com a renda, passou a ser considerada inadequada à justiça na tributação, principalmente se dissociada de seletividade e desacompanhada de níveis razoáveis de distribuição de renda. Já na tributação direta se pôs fim à ideia da proporcionalidade ${ }^{134}$, substituindo-a pela da progressividade em atenção à utilidade

128 GODOI, 1999, p. 173-179.

129 HOMEM, 2014, p. 15-16.

130 Fraternidade (tradução nossa).

131 Liberdade (tradução nossa).

132 Igualdade (tradução nossa).

133 BATISTA JÚNIOR et al., 2015, passim.

134 ALLAN, 1974, p. 42. 
marginal decrescente da renda. De fato, não haveria sentido algum em tributar a menor capacidade contributiva para, de outro lado, fornecer serviços de cujo desfrute o contribuinte fora afastado. Percebia-se que os tributos poderiam ser instrumentos para manter ou agravar as desvantagens das utilidades e das liberdades ${ }^{135}$.

Paralelamente, surgiam propostas defendendo a tributação única e direta sobre o consumo, isto é, sobre a renda gasta. Essa forma de tributação pressupõe que todos devem contribuir em conformidade com a renda líquida. Expoentes dessa tese, no século XX, foram Nicholas Kaldor (1955) e James Meade (1978) propondo um imposto anual, pessoal e progressivo sobre os gastos do contribuinte, para evitar que a renda não consumida pelos indivíduos - a poupança - fosse objeto de tributação. Para essa teoria a tributação incentivaria a poupança e o investimento e sua progressividade levaria à isonomia tributária ${ }^{136}$. No mesmo sentido, a alíquota única sobre o consumo igual a 19\% defendida por Hall e Rabushka (1985) e a ideia de Eugène Shculler, fundador da L'Oréal, de reduzir a tributação à incidente sobre o consumo de energia sob argumento de ser insumo utilizado em todas as formas e etapas de produção de bens e serviços ${ }^{137}$. Ainda que não se reduzisse a uma tributação única, a União Europeia havia seguido essa orientação, tendo instituído em meados do século passado o imposto sobre o consumo, não cumulativo, nos moldes imaginados por Maurice Lauré ${ }^{138}$.

Já no final do século XX, Maurice Allais propunha um tributo sobre o capital à alíquota de $1 \%$, o que abrangeria não apenas as rendas do trabalho e o patrimônio, mas também o

135 SEN, 2010, p. 159.

136 FRANÇA. FALLAIT PAS FAIRE DU DROIT, [s/d], p. 5.

137 BOUVIER, 2002, p. 15.

138 LAURÉ, MAURICE, 1954. 
capital financeiro e especulativo ${ }^{139}$, permitindo que o capital líquido - imobiliário e mobiliário - isto é, a riqueza de um indivíduo, fosse tributada.

Naquele momento, o pagamento de tributos, para além de dever ser conformado à capacidade contributiva de cada um, adquiriria a natureza de um dever jurídico, haja vista os direitos individuais e sociais de cada um e dos demais membros da coletividade e os custos para o Estado da efetivação desses direitos (NABAIS, 1998, p. 684-686).

No Brasil, o princípio da capacidade econômica esteve explicitado no art. 202 da Constituição de 1946 e, posteriormente, no parágrafo $1^{\circ}$ do art. 145 da Constituição de 1988. Ainda que na literalidade esse dispositivo afirme que "sempre que possível os impostos serão pessoais e graduados segundo a capacidade econômica", tanto jurisprudência ${ }^{140}$ quanto doutrina o interpretam como extensivo a todos os tributos e atribuem à capacidade econômica o significado de capacidade contributiva (MACHADO, 1989, p. 125-126), tanto que a redação proposta pela Comissão Afonso Arinos dizia: "os tributos terão caráter pessoal, sempre que isso for possível, e serão graduados pela capacidade econômica do contribuinte" 141 .

Dessa forma, o século $X X$ se encerrou com a consolidação da capacidade contributiva do indivíduo como critério para permitir exigência, para habilitar o sujeito à exação tributária, para graduar a oneração, para garantir o atendimento à proibição do confisco e, principalmente, para cumprimento da isonomia. Estabelecia-se, portanto, um fio condutor para os sistemas tributários e um imperativo categórico para realização da justiça da tributação.

139 FRANÇA, s/d,p. 4.

140 BRASIL, 2011.

141 BRASIL, 19855. 
Chega-se ao século XXI em meio a um confuso processo de globalização em que fronteiras se esfumaçam pelo livre trânsito de fatores e de recursos de produção, principalmente quanto ao capital financeiro ${ }^{142}$. Empresas e moedas - bitcoin, por exemplo - não são mais nacionais.

Nesse contexto, a Organização de Cooperação e de Desenvolvimento Económico (OCDE) apresenta dados preocupantes sobre a concentração de renda e riqueza no mundo ${ }^{143}$.

O renascimento da proposta da Tobin Tax ${ }^{144}$ como um tributo mundial sobe o capital financeiro internacional visando à redução dos efeitos especulativos do capital, cuja arrecadação seria distribuída mundialmente e a ideia de Thomas Piketti ${ }^{145}$ propondo uma tributação sobre o capital - considerado o patrimônio líquido da pessoa física - a ser arrecadado e distribuído mundialmente surgem como propostas para reduzir a espiral de desigualdade.

Instituições como RobinHood Tax Compaign ${ }^{146}$, Association pour la Taxation des Transactions Financières et pour l'Action Citoyenne $^{147}$ (ATTAC), Tax Justice Network ${ }^{148}$ (TJN) e Citizens for Tax Justice ${ }^{149}$ (CTJ) procuram tratar e reduzir a desigualdade enfrentando e considerando o tema tributação.

142 FARIA, 2004, p. 291-296.

143 OECD, 2016.

144 Taxa Tobin (tradução nossa). TOBIN, 1974.

145 PIKETTI, 2014.

146 Campanha de tributação Robin Hood (tradução nossa). THE HOBIN HOOD TAX, s.d.

147 Associação para a tributação das operações financeira e para a ação cidadã (tradução nossa). ATTAC FRANCE, s.d.

148 Rede para a tributação justa (tradução nossa). TAX JUSTICE NETWORK, s.d.

149 Cidadãos por uma tributação justa (tradução nossa). CITZENS FOR TAX JUSTICE, s.d. 
De outro lado, empresas e pessoas adotam medidas agressivas de planejamento tributário com o objetivo de não submeter suas rendas e seu patrimônio à tributação em nenhum lugar do mundo. A internacionalização de grandes companhias vem facilitando o manejo de arranjos legais que proporcionam a redução dos lucros para fins tributários e até mesmo a sua transferência fictícia para localidades de baixa ou nenhuma carga tributária, o que vem sendo combatido por programas como o BEPS (Base Erosion and Profit Shifting ${ }^{150}$ ) da OCDE e o FACTA (Foreign Account Tax Compliance Act ${ }^{151}$ ) dos Estados Unidos da América.

Nesse cenário, o que será uma tributação justa? A constatação de que o fato gerador de um tributo retrata sempre, um acontecimento econômico ${ }^{152}$ resulta, por decorrência lógica, na associação entre a exigência do tributo e a capacidade - individual e concreta - do sujeito que praticou o fato econômico de pagar o tributo.

Por essa razão costuma-se mencionar que pecunia non ole $^{153}$, frase atribuída a Vespasiano para justificar ao seu filho Tito, na Roma do século primeiro, a tributação sobre o uso de mictórios públicos significando que os tributos devem ser exigidos independentemente da validade jurídica dos atos e negócios praticados pelos contribuintes. Julgando o HC 77.530/RS em 25/08/1998, o STF decidiu que "a exoneração tributária dos resultados econômicos de fato criminoso, antes de ser corolário do princípio da moralidade, constitui violação do princípio da isonomia fiscal, de manifesta inspiração ética".

150 Erosão tributária e transferência de lucros (tradução nossa). OECD, Inclusive Framework on BEPS, s.d.

151 Ato de cooperação de informações estrangeiras (tradução nossa). IRS, Foreign Account Tax Compliance Act s.d.

152 HENSEL, 1956, p. 105.

153 O dinheiro não tem cheiro (tradução nossa). 
Essa concepção do fato gerador é denominada teoria da interpretação econômica e privilegia o aspecto material do fato jurídico, considerando irrelevante a forma de que se tenha revestido ${ }^{154}$. De origem alemã, chegou à Itália pelas mãos de Albert Hensel em razão de sua mudança forçada pelo nazismo para Pavia influenciando a Escola formada por Benvenuto Griziotti e Dino Jarach, entre outros. Com a ascensão do fascismo, Dino Jarach - de ascendência judaica como Hensel - foi obrigado pelo regime a sair do país instalando-se Argentina, de onde teria divulgada pela América Latina a teoria da interpretação econômica do fato gerador ${ }^{155}$.

As críticas que a ela se faz devem-se principalmente pela edição em 1934 da Steueranpassungseset $z^{156}$ que permitia a interpretação das leis alemãs e dos fatos tributários segundo as concepções do nacional-socialismo, o que desvirtuava inteiramente a teoria. Todavia, alterações posteriores no CTA corrigiram a deturpação restaurando a original teoria da interpretação econômica do fato gerador.

O Código Tributário brasileiro normatizou essa teoria fazendo constar nos artigos 109 e 118 a possibilidade de interpretação e aplicação da lei tributária independentemente dos efeitos civis dos fatos jurídicos, por influência direta da doutrina alemã ${ }^{157}$. O autor da codificação brasileira já havia escrito que os atos, contratos ou negócios jurídicos cujos efeitos econômicos sejam idênticos devem produzir efeitos tributários também idênticos, muito embora as partes lhes tenham atribuído formas jurídicas diferentes ${ }^{158}$.

154 HENSEL, 1956, p. 143.

155 ATALIBA, 2004, p. 5.

156 Lei de adaptação tributária (tradução nossa). DEUTSCHLAND, Steueranpassungsgesetz, 1934.

157 NOGUEIRA, 1978, p. XI.

158 SOUSA, 1960, p. 70 


\section{Considerações finais}

Sob a cor de síntese final dos argumentos desenvolvidos, a tributação, por ser antes de tudo decorrência de um fato econômico, deve ocorrer se e sempre que tal fato evidencie riqueza tributável (capacidade econômica), incidindo na medida da aptidão do sujeito para pagar o tributo (capacidade contributiva).

Por haver diversidade na capacidade de se produzir riqueza e também nas formas como ocorre a distribuição dessa riqueza produzida, faz-se necessário que a tributação encontre uma multiplicidade de vias de incidência, ainda que todas devam ser baseadas em referências objetivas da capacidade contributiva.

Essa realidade impõe o afastamento das teorias que privilegiam a forma jurídica em detrimento da substância econômica dos fatos, assim como pressupõe a rejeição da adoção de um imposto único em face da diversidade de fatos econômicos.

Um sistema plúrimo deve contemplar algumas das bases econômicas de incidência que possibilitem alcançar a pessoa apta a possuir capacidade contributiva: (i) o patrimônio líquido ou riqueza acumulada; (ii) a renda ganha de todas as origens (rendimentos do trabalho e do capital); (iii) a renda gasta ou o consumo, indicador da diferença entre renda ganha e renda poupada.

Por fim, o exame da tributação justa enfrenta a questão de seus próprios efeitos, cabendo indagar se deve ser neutra, assim considerada aquela que não altera o funcionamento da economia, a alocação de recursos e a distribuição de renda. Essa característica que possuem os tributos de, para além da função fiscal de financiar o Estado, produzir efeitos extrafiscais relativos ao comércio exterior, à produção industrial, 
à proteção ambiental e, principalmente, à distribuição de renda, é importantíssima para a questão da justiça tributária. É preciso, nesse momento, fazer ingressar no palco a teoria do sacrifício, os impostos diretos e a progressividade.

Nesse palco, as taxas - ou impôt-contrepartie ${ }^{159}$ - poderão excepcionalmente ser exigidas, desde que relativamente àqueles serviços específicos e divisíveis cujo uso denote capacidade contributiva - a exemplo dos passaportes e do pedágio.

$\mathrm{Na}$ verdade, o sistema tributário regressivo ${ }^{160}$ implantado no Brasil, em que 70,97\% da carga tributária é representada por tributos indiretos ${ }^{161}$, somente se explica em razão de influências políticas de grupos de interesse, como já reconhecia Sen: "A influência política visando ao ganho econômico é um fenômeno muito real neste mundo em que vivemos" ${ }^{\prime \prime}{ }^{162}$

Defende-se, assim, um sistema tributário plural e solidário formado por impostos pagos pela pessoa física, por se ela o último e final beneficiário de utilidades e liberdades. Acredita-se que essa ideia, ao se aproximar objetivamente da capacidade contributiva, é a que melhor atende à ideia de tributação justa.

Assim, a busca pela tributação ideal segue seu caminho e, ainda que orientada pela capacidade contributiva, lembra o trajeto do navio que passa ao longo da costa seguindo a luz forte do farol que o ilumina sem, entretanto, nunca o alcançar. Enquanto isso, em terra, esperam em vão Estragon e Vladimir.

159 Tributação contraprestacional (tradução nossa).

160 IPEA, 2011, (a)).

161 BRASIL. Carga Tributária no Brasil 2015, 2016.

162 SEN, 2010, p.164. 


\section{Referências bibliográficas}

ADAMS, Charles. For Good and Evil. The impact of taxes on the course of civilization. Lanham: Madison Books, 2001.

ALLAN, Charles M. La Théorie de la Tributación. Madrid: Alianza, 1974.

AMED, Fernando José; NEGREIROS, Plínio José Labriola de Campos. História dos Tributo no Brasil. São Paulo: SINAFRESP, 2000.

ATTAC FRANCE. Disponível em: <https://france.attac. org/attac/qui-sommes-nous>. Acesso em: 22/08/2017.

ATALIBA, Geraldo. Sobre Dino Jarach. In: JARACH, Dino. O fato imponível. Teoria geral do direito tributário substantivo. São Paulo: Revista dos Tribunais, 2004.

BATISTA JÚNIOR, Onofre Alves; OLIVEIRA, Ludmila Mara Monteiro de; MAGALHÃES, Tarcísio Diniz. Liberalismo, desigualdade e direito tributário. Belo Horizonte: Revista Brasileira de Estudos Políticos, n. 110, pp. 217-272, jan./ jun. 2015.

BECKETT, Samuel. En attendant Godot. Paris: De Minuit, 1952.

BERCOVICI, Gilberto. Soberania e Constituição para uma crítica ao constitucionalismo. São Paulo: Martins Fontes, 2001.

BERLIRI, Luigi Vittorio. El Impuesto Justo. Madrid: Instituto de Estudios Fiscales. Ministerio de Economia y Hacienda, 1986.

BOUVIER, Michel. La question de l'impôt ideal. In: L'Impôt. Paris: Dalloz, 2002. 
BRANDÃO, Cláudio. Introdução ao estudo dos direitos humanos. In: BRANDÃO, Cláudio (Coord.) Direitos Humanos e Fundamentais em Perspectiva. São Paulo: Atlas, 2014.

BRASIL. Senado Federal. Anteprojeto Constitucional. Comissão Provisória de Estudos Constitucionais, instituída pelo Decreto $n^{\circ}$ 91.450, de 18 de julho de 1985. Disponível em: <http:/ / www.senado.leg.br/publicacoes/anais/constituinte/AfonsoArinos.pdf. p. 22. Acesso em: 29/08/2017.

BRASIL. Supremo Tribunal Federal. RE 586.693, rel. min. j. 25-5-2011. Diário de Justiça Eletrônico de 22-6-2011. Disponível em: < http:/ / www.stf.jus.br/portal/constituicao/ constituicao.asp>. Acesso em: 29/08/2017.

BRASIL. Supremo Tribunal Federal. RE 562.351, rel. min. Ricardo Lewandowski, j. 4-9-2012, 1ª T, Diário de Justiça Eletrônico de 14-12-2012. Disponível em:< http://www. stf.jus.br/portal/constituicao/constituicao.asp>. Acesso em: $21 / 08 / 2017$

BRASIL. Ministério da Fazenda. Secretaria da Receita Federal do Brasil. Carga Tributária no Brasil 2015: análise por tributos e base de incidência, 2016. Disponível em: http:/ / idg.receita.fazenda.gov.br/dados/receitadata/estudos-e-tributarios-e-aduaneiros/ estudos-e-estatisticas/carga-tributaria-no-brasil/ctb-2015.pdf. Acesso em: 04/04/2017. BUCHANAN, James M., TOLLISON, Robert D. The Theory of Public Choice. Michigan: The University of Michigan Press, 1984.

CASTRO, Augusto Olympio Viveiros de. Tratado dos Impostos. Rio de Janeiro: Imprensa Nacional, 1910.

CITZENS FOR TAX JUSTICE. Disponível em: <http:// www.ctj.org/.>. Acesso em: 22/08/2017. 
COSTA, Regina Helena. Princípio da Capacidade Contributiva. São Paulo: Malheiros, 2003.

DEUTSCHLAND. Steueranpassungsgesetz Disponível em:< http://www.wirtschaftslexikon24.com/d/steueranpassungsgesetzstanpg/steueranpassungsgesetzstanpg. htm. Acesso em 01/10/2017.

DWORKIN, Ronald. A virtude soberana: a teoria e a prática da igualdade. São Paulo: WMF Martins Fontes, 2012.

EINAUDI, Luigi. Mitos y paradojas de la justicia tributaria. Barcelona: Ariel, 1959.

ESCRIBANO, Francisco. La configuracion juridica del deber de contribuir. Perfiles constitucionales. Córdoba: Civitas, 1988.

FARIA, José Eduardo. O direito na economia globalizada. São Paulo: Malheiros, 2004.

FRANÇA. Fallait pas faire du Droit. Les Ideologies Fiscales. s/d. Disponível em:< http://www.fallaitpasfairedudroit. $\mathrm{fr} /$ droit-fiscal/theorie-de-l-impot/206-les-ideologies-fiscales-cours>. Acesso em: 20/08/2017.

. Déclaration des Droits de L'Homme et du Citoyen de 1789, 2005. Disponível em: <http:/ / www.legifrance. gouv.fr/Droit-francais / Constitution/Declaration-des-Droits-de-1-Homme-et-du-Citoyen-de-1789>. Acesso em: 21/08/2017.

. HERODETE. NET. Ferme Générale, 2014. Disponível em: < http://www.herodote. net/Ferme_generale-mot-41.php>. Acesso em: 20/08/2017.

GIARDINA, Emílio. Le basi theoriche del principio dela capacità contributiva. Milano: Giuffrè, 1961. 
GODOI, Marciano Seabra de. Justiça, Igualdade e Direito Tributário. São Paulo: Dialética, 1999.

GONZÁLEZ, Eusebio e PEREZ DE AYALA, José Luís. Curso de Derecho Tributario. T.1. Madrid: Editoria de Derecho Financiero/Editoriales de Derecho Reunidas, 1978.

GRIZIOTTI, Benvenuto. Princípios de ciência de las finanzas. Buenos Aires: Depalma, 1949.

Saggi sui rinnovamento della studio della scienzia delle finanze e del diritto finanziario. Milano: Giuffrè, 1953.

. Prefazioni. In: HENSEL, Albert. Diritto Tributario. Milano: Dott. A. Giuffrè, 1956.

HALL, Robert e RABUSHKA, Alvin. The Flat Tax. Stanford: Hoover Institution, 1985.

HENSEL, Albert. Diritto Tributario. Milano: Dott. A Giuffrè, 1956.

HOMEM, António Pedro Barbas. Conceito de Direitos Humanos. In: BRANDÃO, Cláudio (Coord.) Direitos Humanos e Fundamentais em Perspectiva. São Paulo: Atlas, 2014.

HUGON, Paul. O Imposto. Teoria moderna e principais sistemas. São Paulo: Renascença, 1945.

INGLATERRA. Magna Charta. 1215. Disponível em: <http:/ / www.direitoshumanos.usp.br/index.php/Documentos-anteriores-\% C3\% A0-cria \% C3\% A7\% C3\% A3o-da-Sociedade-das-Na\%C3\%A7\%C3\%B5es-at\%C3\% A9-1919/ magna-carta-1215-magna-charta-libertatum.html>. Acesso em: 21/08/2017.

. The workhouses. s/d. Disponível em:<http:// www.workhouses.org.uk/poorlaws/>. Acesso em: 21/08/2017. 
INSTITUTO DE PESQUISAS ECONÔMICAS APLICADAS (IPEA). Comunicado $n^{\circ}$ 92. Equidade fiscal no Brasil: impactos distributivos da tributação e do gasto social. 19/05/2011. Disponível em:< file:///C:/Users/Acer/ Desktop/Damas/2011\%20 Indicadores_de_Equidade_Sistema_TN_IPEA>.(a)

Nota Técnica 2011. Número 1. Diest. Custo e tempo do processo de execução fiscal promovido pela Procuradoria da Fazenda Nacional. Disponível em: <http:/ / ipea.gov.br/portal/images/stories/PDFs/nota_tecnica/111230_notatecnicadiest1.pdf>. (b)

IRS. Foreign Account Tax Compliance Act. s/d. Disponível em: <https://www.irs.gov/businesses/corporations / foreign-account-tax-compliance-act-fatca $>$. Acesso em: 22/08/2017.

IRS. Tax Quotes. 2017. Disponível em: https://www.irs. gov/newsroom/tax-quotes. Acesso em: 22/08/2017.

JARACH, Dino. O fato imponível. Teoria geral do direito tributário substantivo. São Paulo: Revista dos Tribunais, 2004.

KALDOR, Nicholas. An Expenditure Tax. London: Allen \& Unwin, 1955.

KEYNES, John Maynard. A Teoria Geral do Emprego, do Juro e da Moeda. São Paulo: Nova Cultura, 1988.

KOSELLECK, Reinhart. Crítica e Crise: uma contribuição à patogênese do mundo burguês. Rio de Janeiro: Contraponto/EdUERJ, 1999.

LACERDA, Bruno Amaro. Origens e consolidação da ideia de justiça social. Belo Horizonte: Revista Brasileira de Estudos Políticos, n. 112, pp. 67-88, jan./jun. 2016.

LAURÉ, MAURICE. Toute L'Histoire en un clic. Disponí- 
vel em:<https://www.herodote.net/10_avril_1954-evenement-19540410.php>. Acesso em 22/08/2017

LOCKE, John. II Tratado sobre o Governo Civil. São Paulo: Abril, 1978.

MACHADO, Hugo de Brito. O Princípio da Capacidade Contributiva. In: Caderno de Pesquisas Tributárias 14. São Paulo: Resenha Tributária, 1989.

MARTINS, Ives Gandra. Impostos: comentários ao CTN. Volume 5. São Paulo: Revista dos Tribunais, 1979.

MEADE, James. The structure and reform of direct taxation. London: Allen \& Unwin, 1978.a

MONTESQUIEU, Charles Secondat. Baron de. O Espírito das Leis. São Paulo: Martins Fontes, 2000.

MOSCHETTI, Francesco. Il principio dela capacità contributiva. Padova: CEDAM, 1973.

MURPHY, Liam; NAGEL, Thomas. O mito da propriedade. São Paulo: Martins Fontes, 2005.

MUSGRAVE, Richard A. Finanza pubblica, equità, democrazia. Bologna: Il Mulino, 1995.

NABAIS, José Casalta. A face oculta dos direitos fundamentais: os deveres e os custos dos direitos. In: COSTA, José Manuel da (org). Estudos em homenagem ao Conselheiro José Manuel Cardoso da Costa. Coimbra: Ed. Coimbra, 2003.

. O dever fundamental de pagar impostos.

Coimbra: Almedina, 1998.

NÓBREGA, Cristóvão Barcelos da. História do Imposto de Renda no Brasil, um enfoque da pessoa física (1922-2013). Brasília: Receita Federal: 2014. 
NOGUEIRA, Ruy Barbosa. Novo Código Tributário Alemão. Rio de Janeiro: Forense, 1978.

O'CONNOR, James. USA: a crise do Estado capitalista. Rio de Janeiro: Paz e Terra, 1977.

OECD. Inclusive Framework on BEPS. Disponível em: < http://www.oecd.org/ctp/beps-about.htm>. Acesso em 25/09/2017.

Inequality, 2016. Disponível em: http://www.oecd. org/social/inequality.htm. Acesso em 25/09/2017.

OLIVEIRA, Ricardo Mariz de. Fundamentos do Imposto de Renda. São Paulo: Quartier Latin, 2008.

PEREIRA, Manuel Henrique de Freitas. Fiscalidade. Coimbra: Almedina, 2009.

PIKETTI, Thomas. O capital no século XXI .Rio de Janeiro: Intrínseca, 2014.

PINHO, Diva Benevides. In: PINHO, Diva Benevides (Coord.). Manual de Economia. São Paulo: Saraiva, 1991.

PLATÃO. As leis. Londres: Penguin Books, 1975.

REALE, Miguel. Lições preliminares de direito, São Paulo: Saraiva, 1994.

SABINE, B.E.V. A history of income tax. London: George Allen \& Unwin, 1966.

SAMUELSON, Paul A. Introdução à Análise Macroeconômica. Volume. I. Rio de Janeiro: Agir, 1979

SANCHES, J. L. Saldanha. Justiça Fiscal. Lisboa: Fundação, 2010.

SARTORI, Karina. Fiscalidade na Idade Média: Bártolo de Sassoferrato. In: BALTHAZAR, Ubaldo Cesar (Org.) O 
Tributo na História: da antiguidade à globalização. Florianópolis: Boiteux, 2006.

SCHOUERI, Luís Eduardo. Normas tributárias indutoras e intervenção econômica. Rio de Janeiro: Forense, 2005.

SELIGMAN, Edwin. R. L'Impôt sur le revenu. Paris: Giard et Brière, 1913.

Buenos Aires: Nova, 1973.

SEN, Amartya. Desenvolvimento como liberdade. Companhia de Letras, 2010.

SIDOU, J. M. Othon. A Natureza Social do Tributo. Rio de Janeiro: Forense, 1978.

SILVA, Fernando A. Rezende da. O imposto sobre a renda e a justiça fiscal. Rio de Janeiro: IPEA/INPES, 1974.

SMITH, Adam. A Riqueza das Nações. Volume III. São Paulo: Nova Cultural, 1988.

SOUSA, Rubens Gomes de. Compêndio de legislação tributária. Rio de Janeiro: Financeiras, 1960.

TAVARES, Francisco Muniz. História da Revolução de Pernambuco. Recife: Cia Ed. Pernambuco, 2014.

TAXJUSTICE NETWORK. Disponível em: < https:/ / www. taxjustice.net/>. Acesso em: 22/08/2017.

THE HOBIN HOOD TAX. Disponível em: < http:/ /www. robinhoodtax.org/>. Acesso em: 22/08/2017.

THOREAU, Henry David. A Desobediência Civil. São Paulo: Martin Claret, 2009.

TIPKE, Klaus. Moral Tributaria del Estado y de los contribuyentes. Madrid: Marcial Pons, 2002. 
TIPKE, Klaus e LANG, Joachim. Direito tributário. V. I. Porto Alegre: Fabris, 2008.

TOBIN, James. The new economics one decade older. Princeton: Princeton University Press, 1974.

TORRES, Heleno Taveira. A justiça dos tributos. In: DERZI, Misabel Abreu Machado e MELO, João Paulo Fanucchi de Almeida. (Coord.). Justiça fiscal. Belo Horizonte: DelRey, 2016.

TORRES, Ricardo Lobo. A ideia da Liberdade no Estado Patrimonial e no Estado fiscal. Rio de Janeiro: Renovar, 1991.

VARSANO, Ricardo. Evolução do Sistema Tributário Brasileiro ao Longo do Século: anotações e reflexões para futuras reformas. Texto para discussão $n^{\circ} 405$. IPEA. Pesquisa e Planejamento Econômico, volume 27, número 1, abril 1997. Disponível em: < http://www.ipea.gov.br/agencia/ images/stories/PDFs/TDs/td_0405.pdf >.

VANONI, Ezio. Natureza e interpretação das leis tributárias. Rio de Janeiro: Financeiras, [s/d].

VASCONCELLO, Marco Antonio Sandoval de. In: PINHO, Diva Benevides (Coord.). Manual de Economia .São Paulo: Saraiva, 1991.

WEBBER, Carolyn e WILDAVSKY, Adam. A History of Taxation and Expenditure in the Western World. New York: Simon and Schuster, 1986. 
Recebido em 20/03/2018.

Aprovado em 24/04/2018.

\section{André Felipe Canuto Coelho}

E-mail: afccbgp@hotmail.com

Bruna Estima Borba

E-mail: brunaestimaborba@gmail.com 